\title{
The effect of Quorum sensing inhibitors on the evolution of CRISPR- based phage immunity in Pseudomonas aeruginosa
}

\author{
Jenny M. Broniewski ${ }^{1} \cdot$ Matthew A. W. Chisnall ${ }^{1}$ Nina Molin Høyland-Kroghsbo $\mathbb{1}^{2} \cdot$ Angus Buckling $^{1}$ • \\ Edze R. Westra $\mathbb{1}^{1}$
}

Received: 24 October 2020 / Revised: 15 February 2021 / Accepted: 18 February 2021 / Published online: 10 March 2021

(c) The Author(s) 2021. This article is published with open access

\begin{abstract}
Quorum sensing controls the expression of a wide range of important traits in the opportunistic pathogen Pseudomonas aeruginosa, including the expression of virulence genes and its CRISPR-cas immune system, which protects from bacteriophage (phage) infection. This finding has led to the speculation that synthetic quorum sensing inhibitors could be used to limit the evolution of CRISPR immunity during phage therapy. Here we use experimental evolution to explore if and how a quorum sensing inhibitor influences the population and evolutionary dynamics of $P$. aeruginosa upon phage DMS3vir infection. We find that chemical inhibition of quorum sensing decreases phage adsorption rates due to downregulation of the Type IV pilus, which causes delayed lysis of bacterial cultures and favours the evolution of CRISPR immunity. Our data therefore suggest that inhibiting quorum sensing may reduce rather than improve the therapeutic efficacy of pilus-specific phage, and this is likely a general feature when phage receptors are positively regulated by quorum sensing.
\end{abstract}

\section{Introduction}

The increase in antimicrobial resistance has led to a resurgence of interest in phage therapy, where bacterial viruses (phage) are used to treat bacterial infections [1-4]. Pseudomonas aeruginosa is an important source of nosocomial infections and potential target for phage therapy [5]. In the laboratory, bacteria tend to rapidly evolve resistance to phage [6], which in a clinical setting might limit the efficacy of the therapeutic phage application [2]. Rapid phage resistance evolution is often due to cell surface alterations that interfere with phage adsorption, or the acquisition of CRISPR-based immunity, where bacteria insert phage-derived sequences into

Supplementary information The online version contains supplementary material available at https://doi.org/10.1038/s41396021-00946-6.

Edze R. Westra

E.R.Westra@exeter.ac.uk

1 Biosciences, Environment and Sustainability Institute, University of Exeter, Penryn, UK

2 Department of Plant and Environmental Sciences, University of Copenhagen, Frederiksberg, Denmark
CRISPR loci on the host genome, which are used to detect and destroy the same or closely related phage during future infections [7-10]. In the case of $P$. aeruginosa PA14, both these mechanisms of phage resistance have been shown to evolve at high frequencies in the laboratory, but the dominant mechanism depends on environmental variables, such as the microbial community context in which infections occur [11], the level of phage genetic variation [12], and the force of infection [13, 14]. The force of infection is an important determinant of CRISPR immunity evolution because unlike surfacebased resistance, which carries a fixed fitness cost, CRISPR immunity is associated with an infection-induced fitness cost due to the expression of phage genes prior to clearance of the infection [14, 15]. Hence, in environments with a high force of infection, surface-based resistance is favoured over CRISPR immunity and vice versa. Because evolution of surface-based resistance, but not CRISPR immunity, is associated with virulence tradeoffs [11], being able to manipulate which type of phage resistance evolves and limiting overall resistance development could have important clinical impacts.

It was recently demonstrated that Quorum Sensing (QS) controls expression of the CRISPR-cas immune system in $P$. aeruginosa [16] and in Serratia [17]. Based on these findings it was suggested that chemical QS inhibitors could 
be leveraged to limit the evolution of CRISPR-based immunity in a clinical setting [16]. QS is a well-studied bacterial communication system which allows bacteria to monitor local cell densities based on the concentration of small autoinducer molecules (AIs). P. aeruginosa PA14 encodes several QS systems, including two that use acyl homoserine lactone (AHL) signalling (LasIR and RhIIR), and the PQS system (for Pseudomonas quinolone signal) (reviewed in [18]). The AHL-based QS systems are involved in regulation of around $6 \%$ of the genes encoded by $P$. aeruginosa [19-21], including CRISPR-cas [16] as well as genes involved in virulence and biofilm formation [22]. The LasIR and RhlIR systems are organised in a hierarchical manner with LasIR at the top of the hierarchy $[23,24]$. LasI produces the AHL signal molecule 3-oxoC12-homoserine lactone (3OC12-HSL), which is released from the cell from where it diffuses until it is taken up by the same or other bacteria in the environment. As cell densities increase, the concentration of the 3OC12-HSL autoinducer within cells increase, which is sensed through the LasR receptor. Beyond a threshold in the 3OC12-HSL concentration, LasR-3OC12-HSL complexes activate target genes, including both LasI and RhlIR. RhlI produces the AHL signal molecule C4-homoserine lactone (C4-HSL). This autoinducer is detected by the RhIR receptor, leading to activation of a second wave of QS genes $[25,26]$ (reviewed in [27, 28]).

Because LasIR and RhIIR QS systems control such a broad range of genes, it remains difficult to predict how QS inhibitors impact phage therapy. For example, these QS systems of $P$. aeruginosa activate not only expression of the CRISPR-cas immune system [16] but also that of its Type IV pili [29], which serve as receptors for many Pseudomonas phage [29-34]. Manipulation of QS may therefore affect both the resistance levels of the host and the infectivity levels of the phage that require type IV pili for infection. Since it remains unclear what the overall effect of QS inhibitors is on the efficacy of phage therapy, we measured how chemical inhibition of QS using Baicalein [35] impacts the ecological and evolutionary interaction between $P$. aeruginosa PA14 and its pilusspecific phage DMS3vir under in vitro laboratory conditions. Our data show that QS inhibition triggers phenotypic changes in the bacterial population that result in partial immunity to phage due to reduced adsorption to the host cells, and the resulting decrease in phage infection frequencies favours the evolution of CRISPR immunity over surface-based resistance. These data suggest that inhibition of QS can reduce the efficacy of phage therapy in a clinical context when QS inhibition results in reduced expression of the phage receptor resulting in less frequent successful infections.

\section{Methods}

\section{Bacterial strains and phage}

We used $P$. aeruginosa UCBPP-PA14 (referred to as WT), $P$. aeruginosa UCBPP-PA14 cas7::LacZ (referred to as CRISPR-KO, since it carries a non-functional CRISPR-cas system) [36], a previously described CRISPR-KO-derived surface mutant (referred to as sm) [14], and P. aeruginosa Tn:: pilA (referred to as pilA KO) [37], a CRISPR-cas immune isolate of $P$. aeruginosa UCBPP-PA14 possessing two spacers targeting the phage DMS3vir (referred to as BIM2 - Bacteriophage insensitive Mutant, previously described in [14]), as well as a double synthase mutant strain of $P$. aeruginosa UCBPP-PA14, $\Delta l a s I$ srhll, (referred to as QS mutant) [16]. Cultures were started from a stock stored at $-80{ }^{\circ} \mathrm{C}$ and were grown in M9 media at $37^{\circ} \mathrm{C}$ for 3 days with transfers to fresh media each day to allow acclimatisation. For all infection experiments we used the previously described mu-like phage, DMS3vir [36]. We also used DMS3vir-acrIF1 described in [38], which carries the anti-CRISPR gene acrIF1 that effectively blocks the CRISPR-cas immune systems of $P$. aeruginosa PA14 [38-40] during streak assays to determine the mechanistic basis of phage resistance. Full datasets for all experiments are available at: https://datadryad.org/stash/share/ Tt20sh0vKBz6gkoqKWHkzkSYMUdFj0qMBEiq1tUdAoo.

\section{Evolution experiments}

Infection experiments were carried out in glass vials containing $6 \mathrm{ml}$ of $\mathrm{M} 9$ media with $0.2 \%$ glucose supplemented with $100 \mu \mathrm{M}$ Baicalein (Cayman Chemical) dissolved in DMSO, and $10^{6} \mathrm{cfu} / \mathrm{ml} P$. aeruginosa WT. The same experiment was carried out concurrently with the QS mutant in the presence or absence of $2 \mu \mathrm{M}$ 3OC12-HSL and $10 \mu \mathrm{M}$ C4-HSL (Sigma) dissolved in DMSO. Control treatments received the same amount of DMSO. Total amounts of $10^{4}$ plaque forming units (pfu) (low phage), $10^{7} \mathrm{pfu}$ (mid phage) or $10^{9} \mathrm{pfu}$ (high phage) were added at the same time as the bacteria. Microcosms were incubated at $37^{\circ} \mathrm{C}$ while shaking at $180 \mathrm{rpm}$. Every $24 \mathrm{~h}$ microcosms were sampled and transferred to fresh media at a 1:100 dilution. Samples from the infected cultures were taken prior to each transfer and chloroform treated to kill bacteria as described previously [38]. $5 \mu \mathrm{l}$ of a serial dilution of chloroform treated sample was spotted onto a lawn of sensitive bacteria (CRISPR-KO strain). Plaques were counted and densities were calculated as pfu/ml. Bacteria were sampled at 3 days post infection to analyse the resistance mechanisms that evolved in response to phage infection. 


\section{Resistance mechanism analysis}

To determine whether bacteria had evolved phage resistance, and whether this was surface-based resistance or CRISPR-based immunity, we performed cross-streak assays as described previously [14]. Briefly, bacterial colonies were isolated by plating on LB agar, 24 colonies per replicate were picked at random per replicate, grown overnight in M9 media supplemented with $0.2 \%$ glucose and then streaked across the ancestral phage (DMS3vir) and the phage carrying the anti-CRISPR gene (DMS3viracrIF1) [38]. Colonies which were resistant to the ancestral phage but not the phage carrying an anti-CRISPR gene were classed as CRISPR immune, whereas colonies that were resistant against both DMS3vir and DMS3vir-acrIF1 were classed as having sm (surface mutation) resistance. Colonies that were not resistant to either phage were classed as sensitive. Results were confirmed with PCR of both of the CRISPR loci which $P$. aeruginosa possesses to check for spacer acquisition in WT and QS mutant clones as described previously [14].

\section{Phage adsorption}

WT $P$. aeruginosa was grown for $24 \mathrm{~h}$ in media supplemented with either DMSO (control) or the QS inhibitor. Cultures were centrifuged at $3500 \mathrm{rpm}$ to form a pellet. The supernatant was discarded and the pellets were resuspended in $5 \mathrm{ml}$ of pre-heated $\left(37^{\circ} \mathrm{C}\right)$ medium with or without the QS inhibitor to $\mathrm{OD}_{600}$ 0.2. Cultures were incubated at $37^{\circ} \mathrm{C}, 180 \mathrm{rpm}$ for $3 \mathrm{~h}$ to achieve mid-log phase and then diluted with pre-heated growth medium to a final volume of $15 \mathrm{ml} .6 \mathrm{ml}$ of each sample was taken and stored on ice to be used to quantify bacterial density at the start of the experiment, as described below. The remaining $9 \mathrm{ml}$ was put back in the incubator at $37^{\circ} \mathrm{C}$, $180 \mathrm{rpm}$. One tube of plain growth media was also processed as a control. Cultures were incubated for $5 \mathrm{~min}$ to allow for temperature equilibration. $1 \mathrm{ml}$ of pre-warmed phage in growth media was added to each culture with a final concentration of $2 \times 10^{5} \mathrm{pfu} / \mathrm{ml}$. Cultures were mixed and a sample taken and added to Eppendorf vials containing $100 \mu \mathrm{l}$ of chloroform, vortexed and stored on ice. This process was repeated at 3, 6, 9, 12, 15, 20, 25, 30,40 and $50 \mathrm{~min}$ post infection. Phage densities were calculated by spotting virus samples isolated by chloroform extraction on a lawn of CRISPR KO bacteria. Bacterial densities were determined by plating dilutions of the original cultures, which were taken at the start of the experiment and stored on ice, on LB Agar plates and counting CFUs. The fraction of free phage particles at each time point were calculated relative to the phage titre at $\mathrm{T} 0$.

\section{Phage elimination assays}

To measure CRISPR-mediated phage elimination over longer timespans, we mixed the Bacteriophage Insensitive Mutant BIM2, which possesses 2 spacers targeting DMS3vir in its' CRISPR array with DMS3vir in glass microcosms containing $6 \mathrm{ml}$ of M9 media supplemented with $0.2 \%$ glucose or DMSO with or without a QS inhibitor (100 $\mu \mathrm{M}$ Baicalein $)$ or AIs $(2 \mu \mathrm{M} 3$ OC12-HSL $+10 \mu \mathrm{M} \mathrm{C} 4-$ HSL) and inoculated with $10^{6} \mathrm{cfu} / \mathrm{ml}$ of the BIM. Cells were then infected with $10^{6} \mathrm{pfu} / \mathrm{ml}$ of phage DMS3vir. Vials were incubated at $37{ }^{\circ} \mathrm{C}$ while shaking at $180 \mathrm{rpm}$ for $24 \mathrm{~h}$ and then sampled. Phage titres were determined via chloroform extraction and spot assay, as described above.

\section{Competition experiments}

We measured fitness by competing the BIM2 targeting DMS3vir against either the phage-sensitive CRISPR-KO strain or against the phage-resistant surface mutant (the pilA $\mathrm{KO}$ or sm strain). A CRISPR immune strain with 2 phagetargeting spacers was used to avoid confounding effects from the evolution of "escape phage" that carry mutations in their target sequences [38, 41]. Competitions were performed in glass microcosms containing $6 \mathrm{ml}$ of M9 media with $0.2 \%$ glucose, and containing either the inhibitor $(100 \mu \mathrm{M}$ Baicalein), the autoinducers $(2 \mu \mathrm{M} \quad 3 \mathrm{OC} 12-\mathrm{HSL}+10 \mu \mathrm{M}$ C4-HSL), or both the QS inhibitor and inducers at these same concentrations. Controls contained the same volume of DMSO only. Microcosms were then inoculated with $10^{6}$ colony forming units (cfu)/ml of a 1:1 mix of the competing strains. Cells were infected with $10^{6} \mathrm{pfu} / \mathrm{ml}$ of phage DMS3vir. Vials were incubated at $37{ }^{\circ} \mathrm{C}$ while shaking at $180 \mathrm{rpm}$ for $24 \mathrm{~h}$ and then sampled. The relative frequencies of each strain were determined via serial dilution and plating on $1.5 \% \mathrm{LB}$ agar plates containing $50 \mathrm{mg} / \mathrm{ml} \mathrm{X-gal} \mathrm{(5-bromo-}$ 4-chloro-3-indolyl- $\beta$-D-galactopyranoside). In each competition experiment one of the competing treatments carried the $L a c Z$ gene which produces the enzyme $\beta$-galactosidase, causing colonies to turn blue when grown on media containing X-gal. This allowed us to visually distinguish competing clones for quantification of their relative frequencies. Relative fitness was calculated as rel. fitness $=[$ (fraction strain $\mathrm{A}$ at $\mathrm{t}=\mathrm{x}) *(1-($ fraction stain $\mathrm{A}$ at $\mathrm{t}=0))] /[($ fraction strain $\mathrm{A}$ at $\mathrm{t}=0) *(1-($ fraction strain $\mathrm{A}$ at $\mathrm{t}=\mathrm{x})])$.

\section{Motility assays}

P. aeruginosa WT or the QS mutant were streaked onto $1.5 \% \mathrm{LB}$ agar plates and grown overnight at $37^{\circ} \mathrm{C}$. In total, $6 \mathrm{ml} \mathrm{M} 9$ media was supplemented with $0.2 \%$ glucose and was inoculated with either the WT or QS mutant and grown for $24 \mathrm{~h}$ at $37^{\circ} \mathrm{C}$, while shaking at $180 \mathrm{rpm}$. Swimming 
ability was determined by inserting a pipette tip containing WT bacteria or the QS mutant halfway through a $0.3 \%$ LB agar plate. Swarming assays were performed by spotting $5 \mu \mathrm{l}$ of undiluted liquid culture onto a $0.5 \% \mathrm{LB}$ agar plate. All motility assay plates were incubated for $24 \mathrm{~h}$ at $37^{\circ} \mathrm{C}$. Motility was measured as the diameter of bacterial growth in $\mathrm{mm}$ at the widest point which intersected the point of inoculation.

\section{Results}

\section{The effect of QS inhibition on phage resistance evolution}

To measure whether chemical QS inhibitors can indeed be used to limit the evolution of CRISPR-based immunity against a pilus-specific phage, we exposed WT PA14 to either $10^{4}, 10^{7}$ or $10^{9}$ pfu of phage DMS3vir in the presence or absence of Baicalein, a potent QS inhibitor [35] (Fig. 1).

In our control, (WT supplemented with DMSO) evolution of CRISPR-based immunity decreased (and surfacebased resistance (sm) increased) with increasing phage titre, as reported previously $[11,13,14]$, with almost all bacteria having evolved CRISPR immunity in the low phage treatment compared to around three quarters of the population in the mid and high phage treatments (Fig. 1). However, when
QS inhibitors were added, we observed changes in the patterns of phage resistance evolution that were contrary to our expectation of a general reduction in CRISPR-mediated immunity. Specifically, in the presence of a QS inhibitor there was a significant increase in the persistence of phage-sensitive bacteria during infection with $10^{4} \mathrm{pfu}$ (Mann-Whitney $\mathrm{U}=3, p<0.05)$ or $10^{7}$ pfu $(\mathrm{U}=1, p<$ $0.01)$ of DMS3vir. Inhibition of QS was also associated with a reduction in the evolution of CRISPR immunity upon infection with $10^{4} \mathrm{pfu}$ of phage $(\mathrm{U}=0, p<0.01)$, or a reduction in sm resistance upon infection with $10^{7}$ pfu of phage $(\mathrm{U}=0, p<0.01)$. The persistence of sensitive bacteria in QS inhibitor treatments was no longer observed when bacteria were infected with $10^{9}$ pfu of phage DMS3vir. Under those conditions, levels of CRISPR immunity were slightly higher compared to the control, and levels of sm resistance were slightly reduced.

\section{The effect of QS inhibition on phage receptor expression}

We envisaged two possible reasons why in the presence of Baicalein the evolution of phage resistance might be reduced upon infection with $10^{4}$ or $10^{7}$ pfu of DMS3vir. First, it may be the case that phage amplification is less efficient in the presence of the QS inhibitor, resulting in weaker selection for resistance. Second, QS inhibition may

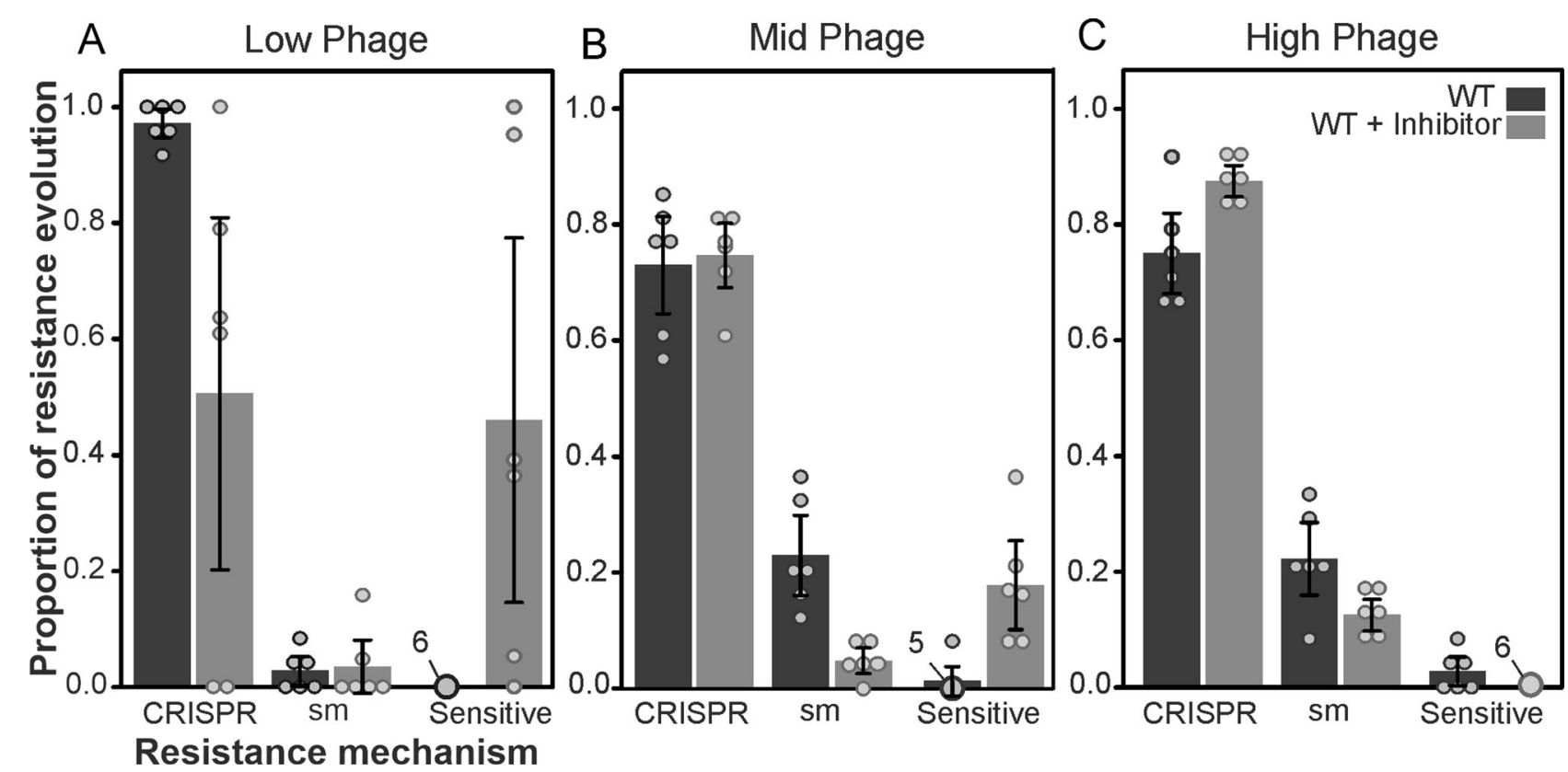

Fig. 1 Inhibiting QS results in reduced phage sensitivity and prolonged phage persistence at low phage densities. Observed resistance mechanism evolution in $P$. aeruginosa PA14 WT or surface mutant (sm) supplemented with DMSO (dark grey bars/points) or $100 \mu \mathrm{M}$ QS inhibitor Baicalein (light grey bars/points) and at 3 days post infection with (A) $10^{4}$ pfu (B) $10^{7}$ pfu (C) $10^{9}$ pfu of phage
DMS3vir. Bars represent mean proportions of each of the different bacterial phenotypes (i.e., the proportion of bacteria in the population that evolved CRISPR immunity, acquired surface mutations or that remained sensitive), error bars indicate $95 \%$ confidence interval, points represent individual replicates, $N=6$. 
A

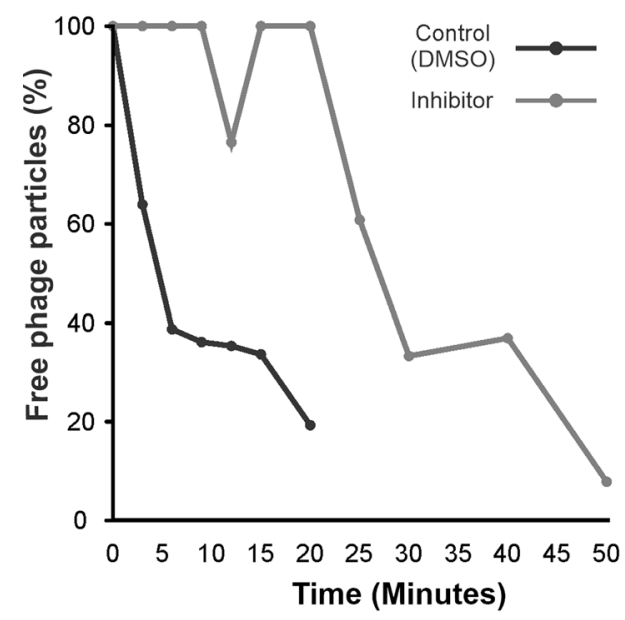

Fig. 2 Phage are less able to infect hosts when QS is inhibited. A Phage adsorption over time $(3-50 \mathrm{~min})$ when WT $P$. aeruginosa is infected with phage when supplemented with DMSO (control) (dark grey line) or $100 \mu \mathrm{M}$ QS inhibitor Baicalein (light grey line). Samples were taken at $3,6,9,12,15,20,25,30,40$ and 50 min post infection. Lines represent mean $\%$ of free phage particles detected, $N=3(\mathbf{B})$

cause cells to downregulate the phage receptors, if these are also regulated by QS [42, 43], which would cause them to become more resistant to phage infection. Indeed, the Type IV Pilus (T4P), which is the receptor of many Pseudomonas phage including DMS3vir [29-34, 44], is known to be regulated by QS, and manipulation of QS can therefore affect phage sensitivity [29]. To test the first hypothesis, we monitored the phage densities throughout the evolution experiment described above. This showed that in the presence of the QS inhibitor, phage amplification was higher than or equal to that observed in the control (Fig. S1). Reduced phage amplification can therefore not explain the results of this experiment.

To test the second hypothesis, that phage receptor expression is affected by QS inhibition, we measured the impact of Baicalein on $P$. aeruginosa PA14 swarming motility, a QS-regulated group behaviour which requires T4P and flagella activity [45-48]. This analysis showed that the lasI rhlI QS mutant was less able to swarm compared to WT cells $(p<0.0001)$ and that WT cells grown in the presence of the QS inhibitor Baicalein were no different in swarming ability to that of the QS mutants $(p>0.9)$ (Fig. S2A). As a control, we also measured swimming motility of the WT strain, which is known to be an individual behaviour driven only by flagella activity [49]. As expected, there was no significant effect of Baicalein on swimming motility in the WT and the lasI rhlI QS mutant strains ( $p>$ 0.1 in all cases) (Fig. S2B). Collectively, these data therefore confirm that QS inhibition using Baicalein inhibits a QS-controlled T4P-dependent group behaviour in PA14.



Treatment

Titre of phage remaining at 24hpi of a CRISPR resistant host possessing two unique spacers targeting the infecting phage (BIM2) when initially infected with $10^{9}$ phage. Bars represent mean titre of phage present at $24 \mathrm{hpi}$, error bars indicate $95 \%$ confidence interval, points represent individual replicates, $N=6, \mathrm{Y}$ axis is $\log ^{10}$ scale.

\section{The effect of QS inhibition on phage adsorption}

Next, to investigate how these phenotypic changes induced by the presence of baicalein affect the infectivity of phage DMS3vir, we measured whether Baicalein affects phage adsorption. To this end, we infected WT $P$. aeruginosa PA14 cells in exponential growth phase with phage DMS3vir at a multiplicity of infection of 0.01 and measured phage titres over $50 \mathrm{~min}$ in the presence or absence of Baicalein (Fig. 2A). This revealed that phage took significantly longer to adsorb to host cells when the QS inhibitor was added to the media (Welch's $t$ test $\mathrm{T}=2.548, \mathrm{DF}=13.78$, $p<0.05)$ supporting the hypothesis that QS inhibition leads to a reduction in the rate of phage DMS3vir adsorption.

Previous work has shown that CRISPR immune bacteria cause a decline in phage densities because of their ability to continually remove phage from the population [38, 50], However only phage that adsorb to the bacterial cell and inject their genome will be targeted and removed via CRISPR-Cas activity. We therefore hypothesized that the decrease in phage adsorption observed when baicalein was present would result in higher phage titres. To test this hypothesis we infected CRISPR immune bacteria with $10^{9} \mathrm{pfu}$ of DMS3vir in the presence or absence of Baicalein or synthetic autoinducers and measured phage titres after $24 \mathrm{~h}$ of infection (Fig. 2B). This showed that phage titres were only slightly above the threshold of detection after $24 \mathrm{~h}$ of infection in the control treatments. However, there was a significant decrease in the amount of phage that had been removed by CRISPR immune bacteria in the presence 
of the QS inhibitor (Mann-Whitney $\mathrm{U}=0, p<0.01$ ) or the inhibitor and AIs combined $(\mathrm{U}=0, p<0.01)$. This is consistent with the reduction in phage adsorption in the presence of the QS inhibitors (Fig. 2A), since this leads to fewer infections and therefore a reduction in phage removal by CRISPR immune bacteria.

\section{The fitness effects of QS inhibition for immune, resistant and sensitive bacteria}

Collectively, these data led us to predict that applying Baicalein may reduce the efficacy of phage-mediated killing by enhancing the intrinsic levels of phage resistance of the bacteria. To test this, we measured how Baicalein affects the fitness of phage sensitive bacteria in the presence of phage, by competing sensitive bacteria lacking a functional CRISPR-cas immune system (CRISPR KO strain) against a pilus deletion mutant (a PilA KO strain) that lacks the T4P and is fully resistant to phage DMS3vir. This showed that sensitive bacteria were always outcompeted by the pilus deletion strain in the presence of phage, as expected. However, sensitive bacteria had a significantly higher fitness when Baicalein was added to those competition experiments (Mann-Whitney $\mathrm{U}=0, p<0.005$ ) (Fig. 3A). These data therefore confirm that Baicalein increases the resistance levels of bacteria against pilus-specific phage, hence lowering the infectivity of the phage and potentially the efficacy of phage therapy cocktails containing baicalein.

We speculated that the reduced phage adsorption in the presence of Baicalein may also explain the high levels of CRISPR immunity and low levels of sm resistance that evolve under the highest phage exposure levels (Fig. 1). CRISPR immunity is associated with an infection-induced fitness cost, whereas sm is associated with a fixed cost [14]. As a consequence, inhibition of QS and phage adsorption could lead to an enhanced fitness of CRISPR immune bacteria relative to surface mutants. Indeed, direct competition between a CRISPR immune clone (BIM2) and a bacterium with surface-based resistance $(\mathrm{sm})$ revealed that the relative fitness of BIM2 increased in the presence of Baicalein (Mann-Whitney $\mathrm{U}=0, p<0.005$ ), and was not affected by the addition of AIs $(\mathrm{U}=17, p>0.9)$ (Fig. 3B). Both the sm strain and BIM2 possess complete immunity against the infecting phage (no plaques observed). While the sm strain has a slightly higher fitness during phage infection in the absence of QS manipulation, the relative fitness of BIM2 is higher than that of the sm strain when QS is inhibited. The increased fitness of CRISPR immune bacteria further supports the idea that they are infected at a lower frequency when QS is inhibited.

Finally, given that CRISPR immune bacteria are less efficient in removing phage in the presence of Baicalein (Fig. 2), and sensitive bacteria will be affected by the presence of the phage more strongly than CRISPR immune bacteria, we hypothesized the outcome of direct competition between CRISPR immune bacteria and sensitive bacteria is likely to be also affected by Baicalein. Direct competition between CRISPR immune bacteria and sensitive bacteria showed that CRISPR immune bacteria outcompete sensitive bacteria in the presence of phage, as expected. Crucially, the fitness of CRISPR immune bacteria relative to sensitive bacteria increased in the presence of Baicalein $(\mathrm{U}=2, p<$
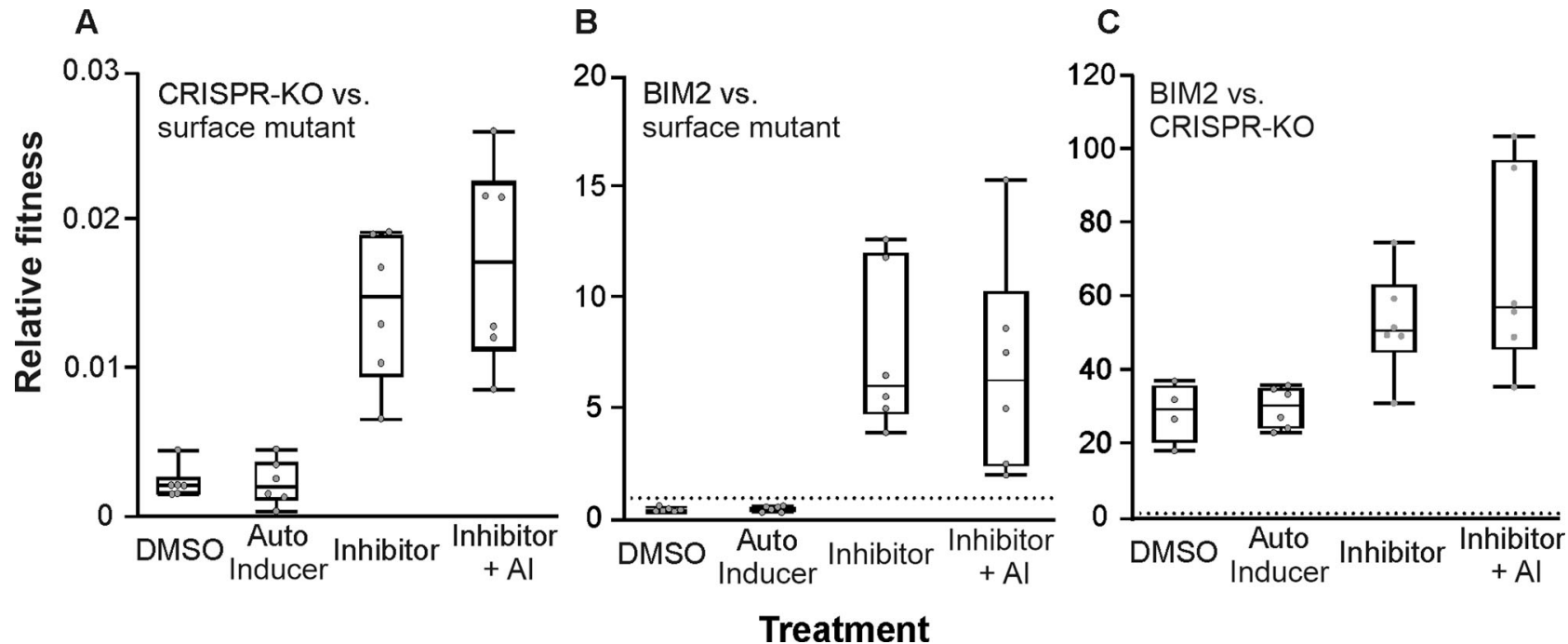

Fig. 3 Inhibiting QS increases the fitness of $P$. aeruginosa in the presence of $10^{6}$ pfu of phage. A Relative fitness of sensitive CRISPRKO strain during competition with the phage resistant surface mutant (sm). B Relative fitness of BIM2 during competition with a phage resistant surface mutant $(\mathrm{sm})$. C Relative fitness of BIM2 during competition with a sensitive CRISPR-KO strain. Box plots show the median, 25th and 75th percentile, and the interquartile range. Raw values from each replicate are shown as points, $N=6$. Dotted line in panels ( $\mathbf{B}$ and $\mathbf{C}$ ) indicates the point at which competing strains are equally fit (when relative fitness $=1$ ). 
0.05) (Fig. 3C). By contrast, the addition of synthetic AIs had no significant impact on the relative fitness of the CRISPR immune bacteria (Mann-Whitney $\mathrm{U}=11, p>$ 0.9 ), which suggests that QS systems may already be saturated under the conditions used here.

\section{Discussion}

$P$. aeruginosa is one of the leading pathogens responsible for nosocomial infections and the most important pathogen associated with chronic airway infections in cystic fibrosis patients [51]. The rapid increase in antimicrobial resistance has led to many $P$. aeruginosa infections being very difficult to eradicate [52]. Phage therapy is therefore considered a viable alternative or complementary treatment of $P$. aeruginosa infections, and some experimental studies and clinical case studies have shown promising results [53]. However, evolution of phage resistance may limit the longterm effectiveness of phage-based therapeutics. One way to limit the evolution of phage resistance by $P$. aeruginosa is by using cocktails of different phages that use different receptors, since in this case multiple mutations in different receptor genes are needed to resist all phages [54]. When bacteria encode a CRISPR-Cas immune system, as is the case for approximately half of all sequenced $P$. aeruginosa isolates [55], this strategy may become less effective, since bacteria can in principle pick up multiple spacers that target the different phage in the cocktail [56-59]. Being able to limit the evolution of CRISPR immunity could have important clinical impact, since bacteria that remain phage sensitive or evolve CRISPR immunity are more likely to retain their virulence levels compared to bacteria that evolve surface-based resistance [11, 60, 61].

In the experiments presented here we tested the hypothesis that, because QS regulates CRISPR-cas expression [16, 62], chemical inhibition of QS might enhance the efficacy of phage-mediated killing of bacteria and steer evolution of phage resistance away from CRISPR immunity and towards surface-based resistance. However, in contrast to the predicted synergy between Baicalein and phage, we found that these compounds have antagonistic effects. Specifically, we found that Baicalein increased survival of sensitive bacteria and increased the fitness of sensitive and CRISPR immune bacteria relative to surface mutants. This is because QS also regulates expression of the T4P [29], which is used as a receptor by many Pseudomonas phage, including phage DMS3vir [44]. As a consequence, the rate of phage adsorption is reduced in the presence of Baicalein, which favours CRISPR immune bacteria over surface mutants likely because of their induced and fixed costs of resistance, respectively [14]. This shows that QS inhibition may have unanticipated effects on the evolutionary outcome of bacteria-phage interactions.

Such antagonistic effects are expected when host factors that are important for phage infection and/or replication are positively regulated by QS, whereas synergistic interactions between QS inhibitors and phage are more likely when QS downregulates the expression of phage receptors. Experimental studies with Escherichia coli have demonstrated QSmediated downregulation of receptors used by its phage Lambda and Chi at high cell densities [43] and similar findings were reported for Vibrio anguillarium, which was more resistant to infection by its phage KVP40 at high cell densities due to QS-mediated downregulation of the phage receptor OmpK [42]. In the case of $P$. aeruginosa, the vast majority of phage characterized to date appear to either use lipopolysaccharides or the T4P as their receptor [33]. While this work shows that synergy is unlikely between pilusspecific phage and QS inhibitors, synergy between Baicalein and LPS-specific phage remains an exciting possibility that awaits experimental examination in future studies.

Manipulation of bacterial QS may also directly impact phage infection dynamics (i.e., independent of changes in host gene expression). Some temperate phage carry QS receptors [63] that can bind the autoinducers produced by the host they infect [64]. A prophage of Vibrio cholera that carries the QS receptor VqmA uses the autoinducers produced by the host as a cue for prophage induction when cell densities of the host are high [65]. Other temperate phage encode their own QS systems, known as Arbitrium systems, and preferentially enter the prophage state once the signal concentration becomes high, presumably because this indicates that available hosts are running out [66]. These examples highlight the importance of QS in shaping the epidemiology of phage, and manipulation of QS could conceivably alter infection dynamics and the mobility of some phage within microbial communities, which could have important implications for the bacterial population dynamics.

In summary, QS inhibitors offer exciting opportunities to manipulate the expression of genes that underpin phage resistance and clinically important traits and group behaviours such as the expression of virulence determinants [67], toxin production [68], biofilm formation [69], and swarming motility [45]. Because of the many phenotypes controlled by QS, the phenotypic, population dynamics and evolutionary consequences of QS inhibitors are difficult to predict, and experimental tests in laboratory settings and more ecologically relevant infection models will be critical to understand if and how these chemicals can be used in a clinical context and in combination with which phage.

Acknowledgements We thank Alexandro Rodriguez Rojas for kindly providing $P$. aeruginosa UCBPP-PA14 MAR2xT7::mutS and Bonnie 
L. Bassler for providing the double synthase $\Delta$ lasI $\Delta$ rhlI quorum sensing mutant strain of $P$. aeruginosa UCBPP-PA14.

Funding JMB and MAWC are supported by a studentship and a grant from the Biotechnology and Biological Science Research Council (BBSRC; BB/N017412/1, awarded to ERW). NMHK was supported by Lundbeck Foundation grants R220-2016-860 and R264-20173936. ERW was further supported by the Natural Environment Research Council (http://www.nerc.ac.uk) (NE/M018350/1) and a grant from the European Research Council (https://erc.europa.eu) (ERC-STG-2016-714478 - EVOIMMECH). AB was supported by funding from The Royal Society.

Author contributions ERW, NMHK and JMB conceived and designed the study. JMB and MAWC performed the experiments. JMB, MAWC and ERW analysed and interpreted the data. JMB and ERW drafted the article, which was further edited by NMHK, MAWC and AB. All authors approved the version to be published.

\section{Compliance with ethical standards}

Conflict of interest The authors declare no competing interests.

Publisher's note Springer Nature remains neutral with regard to jurisdictional claims in published maps and institutional affiliations.

Open Access This article is licensed under a Creative Commons Attribution 4.0 International License, which permits use, sharing, adaptation, distribution and reproduction in any medium or format, as long as you give appropriate credit to the original author(s) and the source, provide a link to the Creative Commons license, and indicate if changes were made. The images or other third party material in this article are included in the article's Creative Commons license, unless indicated otherwise in a credit line to the material. If material is not included in the article's Creative Commons license and your intended use is not permitted by statutory regulation or exceeds the permitted use, you will need to obtain permission directly from the copyright holder. To view a copy of this license, visit http://creativecommons. org/licenses/by/4.0/.

\section{References}

1. Salmond GPC, Fineran PC. A century of the phage: past, present and future. Nat Rev Microbiol. 2015;13:777-86.

2. Levin BR, Bull JJ. Population and evolutionary dynamics of phage therapy. Nat Rev Microbiol. 2004;2:166-73.

3. Gordillo Altamirano FL, Barr JJ. Phage therapy in the postantibiotic era. Clin Microbiol Rev. 2019;32:2.

4. Kortright KE, Chan BK, Koff JL, Turner PE. Phage therapy: a renewed approach to combat antibiotic-resistant bacteria. Cell Host Microbe. 2019;25:219-32.

5. Tümmler B. Emerging therapies against infections with Pseudomonas aeruginosa. F1000Res. 2019;8:F1000 Faculty Rev-1371. https://doi.org/10.12688/f1000research.19509.1. eCollection 2019.

6. Buckling A, Brockhurst M. Bacteria-virus coevolution. Adv Exp Med Biol. 2012;751:347-70. https://doi.org/10.1007/978-1-46143567-9_16.

7. Hampton HG, Watson BNJ, Fineran PC. The arms race between bacteria and their phage foes. Nature 2020;577:327-36.

8. Makarova KS, Wolf YI, Iranzo J, Shmakov SA, Alkhnbashi OS, Brouns SJJ, et al. Evolutionary classification of CRISPR-Cas systems: a burst of class 2 and derived variants. Nat Rev Microbiol. 2020;18:67-83.
9. Rostøl JT, Marraffini L. (Ph)ighting phage: how bacteria resist their parasites. Cell Host Microbe. 2019;25:184-94.

10. Hille F, Richter H, Wong SP, Bratovič M, Ressel S, Charpentier E. The biology of CRISPR-Cas: backward and forward. Cell 2018;172:1239-59.

11. Alseth EO, Pursey E, Luján AM, McLeod I, Rollie C, Westra ER. Bacterial biodiversity drives the evolution of CRISPR-based phage resistance. Nature. 2019;574:549-52.

12. Broniewski JM, Meaden S, Paterson S, Buckling A, Westra ER. The effect of phage genetic diversity on bacterial resistance evolution. ISME J. 2020;2:1-9.

13. Chabas H, Van Houte S, Høyland-Kroghsbo NM, Buckling A, Westra ER. Immigration of susceptible hosts triggers the evolution of alternative parasite defence strategies. Proc R Soc B Biol Sci. 2016;283:20160721.

14. Westra ER, Van Houte S, Oyesiku-Blakemore S, Makin B, Broniewski JM, Best A, et al. Parasite exposure drives selective evolution of constitutive versus inducible defense. Curr Biol. 2015;25:1043-9.

15. Meaden S, Capria L, Alseth E, Gandon S, Biswas A, Lenzi L, et al. Phage gene expression and host responses lead to infectiondependent costs of CRISPR immunity. ISME J. 2021;15:534-4. https://doi.org/10.1038/s41396-020-00794-w.

16. Høyland-Kroghsbo NM, Paczkowski J, Mukherjee S, Broniewski J, Westra E, Bondy-Denomy J, et al. Quorum sensing controls the Pseudomonas aeruginosa CRISPR-Cas adaptive immune system. Proc Natl Acad Sci USA. 2016;114:201617415.

17. Patterson AG, Jackson SA, Taylor C, Evans GB, Salmond GPC, Przybilski R, et al. Quorum sensing controls adaptive immunity through the regulation of multiple CRISPR-Cas systems. Mol Cell. 2016;64:1102-8.

18. Ahator SDela, Zhang LH. Small is mighty-chemical communication systems in Pseudomonas aeruginosa. Annu Rev Microbiol. 2019;73:559-78.

19. Schuster M, Lostroh CP, Ogi T, Greenberg EP. Identification, timing, and signal specificity of Pseudomonas aeruginosa quorumcontrolled genes: a transcriptome analysis. J Bacteriol. 2003; 185:2066-79.

20. Wagner VE, Bushnell D, Passador L, Brooks AI, Iglewski BH. Microarray analysis of Pseudomonas aeruginosa quorum-sensing regulons: effects of growth phase and environment. J Bacteriol. 2003; 185:2080-95.

21. Vasil ML. DNA microarrays in analysis of quorum sensing: strengths and limitations. J Bacteriol. 2003;185:2061-5.

22. Turkina MV, Vikström E. Bacteria-host crosstalk: sensing of the quorum in the context of pseudomonas aeruginosa infections. $\mathrm{J}$ Innate Immun. 2019;11:263-79.

23. Lee J, Zhang L. The hierarchy quorum sensing network in Pseudomonas aeruginosa. Protein Cell. 2014;6:26-41.

24. Defoirdt T. Quorum-sensing systems as targets for antivirulence therapy. Trends Microbiol. 2018;26:313-28.

25. Pearson JP, Passador L, Iglewski BH, Greenberg EP. A second Nacylhomoserine lactone signal produced by Pseudomonas aeruginosa. Proc Natl Acad Sci. 1995;92:1490-4.

26. O'Loughlin CT, Miller LC, Siryaporn A, Drescher K, Semmelhack MF, Bassler BL. A quorum-sensing inhibitor blocks Pseudomonas aeruginosa virulence and biofilm formation. Proc Natl Acad Sci. 2013;110:17981-6.

27. Papenfort K, Bassler BL. Quorum sensing signal-response systems in Gram-negative bacteria. Nat Rev Microbiol. 2016;14:576-88.

28. Whiteley M, Diggle SP, Greenberg EP. Progress in and promise of bacterial quorum sensing research. Nature. 2017;551:313-20.

29. Glessner A, Smith RS, Iglewski BH, Robinson JB. Roles of Pseudomonas aeruginosa las and rhl quorum-sensing systems in control of twitching motility. J Bacteriol. 1999;181:1623-9. 
30. Bradley DE. A study of pili on Pseudomonas aeruginosa. Genet Res. 1972;19:39-51.

31. Bradley DE. Evidence for the retraction of Pseudomonas aeruginosa RNA phage pili. Biochem Biophys Res Commun. 1972;47:142-9.

32. Bradley DE. Basic characterization of a Pseudomonas aeruginosa pilus-dependent bacteriophage with a long noncontractile tail. J Virol. 1973;12:1139-48.

33. Bondy-Denomy J, Qian J, Westra ER, Buckling A, Guttman DS, Davidson AR, et al. Prophage mediate defense against phage infection through diverse mechanisms. ISME J. 2016;10:2854-66.

34. Chung IY, Jang HJ, Bae HW, Cho YH. A phage protein that inhibits the bacterial ATPase required for type IV pilus assembly. Proc Natl Acad Sci USA. 2014;111:11503-8.

35. Zeng Z, Qian L, Cao L, Tan H, Huang Y, Xue X, et al. Virtual screening for novel quorum sensing inhibitors to eradicate biofilm formation of Pseudomonas aeruginosa. Appl Microbiol Biotechnol. 2008;79:119.

36. Cady KC, Bondy-Denomy J, Heussler GE, Davidson AR, O'Toole GA. The CRISPR/Cas adaptive immune system of Pseudomonas aeruginosa mediates resistance to naturally occurring and engineered phage. J Bacteriol. 2012;194:5728-38.

37. Liberati NT, Urbach JM, Miyata S, Lee DG, Drenkard E, Wu G, et al. An ordered, nonredundant library of Pseudomonas aeruginosa strain PA14 transposon insertion mutants. Proc Natl Acad Sci. 2006;103:2833-8.

38. van Houte S, Ekroth AKE, Broniewski JM, Chabas H, Ashby B, Bondy-Denomy $\mathrm{J}$, et al. The diversity-generating benefits of a prokaryotic adaptive immune system. Nature. 2016;532:385-8.

39. Landsberger M, Gandon S, Meaden S, Rollie C, Chevallereau A, Chabas $\mathrm{H}$, et al. Anti-CRISPR phage cooperate to overcome CRISPR-Cas immunity. Cell. 2018;174:908-16.

40. Chevallereau A, Meaden S, Fradet O, Landsberger M, Maestri A, Biswas A, et al. Exploitation of the cooperative behaviors of AntiCRISPR phage. Cell Host Microbe. 2019;27:189-98.

41. Levin BR, Moineau S, Bushman M, Barrangou R. The population and evolutionary dynamics of phage and bacteria with CRISPRmediated immunity. PLoS Genet. 2013;9:e1003312.

42. Tan D, Svenningsen SLO, Middelboe M. Quorum sensing determines the choice of antiphage defense strategy in Vibrio anguillarum. MBio. 2015;6:e00627-15.

43. Høyland-Kroghsbo NM, Mærkedahl RB, Svenningsen SLO. A quorum-sensing-induced bacteriophage defense mechanism. MBio. 2013;4:e00362-12.

44. Budzik JM, Rosche WA, Rietsch A, O'Toole GA. Isolation and characterization of a generalized transducing phage for Pseudomonas aeruginosa strains PAO1 and PA14. J Bacteriol. 2004;186:3270-3.

45. Shrout JD, Chopp DL, Just CL, Hentzer M, Givskov M, Parsek MR. The impact of quorum sensing and swarming motility on Pseudomonas aeruginosa biofilm formation is nutritionally conditional. Mol Microbiol. 2006;62:1264-77.

46. Reimmann C, Ginet N, Michel L, Keel C, Michaux P, Krishnapillai $\mathrm{V}$, et al. Genetically programmed autoinducer destruction reduces virulence gene expression and swarming motility in Pseudomonas aeruginosa PAO1. Microbiology. 2002;148:923-32.

47. Tremblay J, Richardson AP, Lépine F, Déziel E. Self-produced extracellular stimuli modulate the Pseudomonas aeruginosa swarming motility behaviour. Environ Microbiol. 2007;9:2622-30.

48. Kohler T, Curty LK, Barja F, Van Delden C, Pechere JC. Swarming of Pseudomonas aeruginosa is dependent on cell-to-cell signaling and requires flagella and pili. J Bacteriol. 2000;182:5990-6.
49. Ha D-G, Kuchma SL, O’Toole GA. Plate-based assay for swimming motility in pseudomonas aeruginosa. Methods Mol Biol. 2014;1149:59-65. https://doi.org/10.1007/978-1-4939-0473-0_7.

50. Rollie C, Chevallereau A, Watson BNJ, Chyou Tyuan, Fradet O, McLeod I, et al. Targeting of temperate phage drives loss of type I CRISPR-Cas systems. Nature. 2020;578:149-53.

51. Winstanley C, O'Brien S, Brockhurst MA. Pseudomonas aeruginosa evolutionary adaptation and diversification in cystic fibrosis chronic lung infections. Trends Microbiol. 2016;24:327-37.

52. Deredjian A, Colinon C, Brothier E, Favre-Bonté S, Cournoyer B, Nazaret S. Antibiotic and metal resistance among hospital and outdoor strains of Pseudomonas aeruginosa. Res Microbiol. 2011;162:689-700.

53. De Smet J, Hendrix H, Blasdel BG, Danis-Wlodarczyk K, Lavigne R. Pseudomonas predators: Understanding and exploiting phage-host interactions. Nat Rev Microbiol. 2017;15:517.

54. Wright RCT, Friman VP, Smith MCM, Brockhurst MA. Crossresistance is modular in bacteria-phage interactions. PLoS Biol. 2018; 16:e2006057.

55. van Belkum A, Soriaga LB, LaFave MC, Akella S, Veyrieras JB, Barbu EM, et al. Phylogenetic distribution of CRISPR-Cas systems in antibiotic- resistant pseudomonas aeruginosa. MBio. 2015;6: e01796-15. https://doi.org/10.1128/mBio.01796-15.

56. Paez-Espino D, Morovic W, Sun CL, Thomas BC, Ueda KI, Stahl $\mathrm{B}$, et al. Strong bias in the bacterial CRISPR elements that confer immunity to phage. Nat Commun. 2013;4:1-7.

57. Andersson AF, Banfield JF. Virus population dynamics and acquired virus resistance in natural microbial communities. Science. 2008;320:1047-50.

58. Weinberger AD, Sun CL, Pluciński MM, Denef VJ, Thomas BC, Horvath $\mathrm{P}$, et al. Persisting viral sequences shape microbial CRISPR-based immunity. PLoS Comput Biol. 2012;8:e1002475.

59. Weissman JL, Fagan WF, Johnson PLF. Selective Maintenance of Multiple CRISPR Arrays Across Prokaryotes. Cris J. 2018;1:405-13.

60. León M, Bastías R. Virulence reduction in bacteriophage resistant bacteria. Front Microbiol. 2015;6:343.

61. Craig L, Pique ME, Tainer JA. Type IV pilus structure and bacterial pathogenicity. Nat Rev Microbiol. 2004;2:363-78.

62. Høyland-Kroghsbo NM, Muñoz KA, Bassler BL. Temperature, by controlling growth rate, regulates CRISPR-cas activity in pseudomonas aeruginosa. MBio. 2018:9:e02184-18. https://doi. org/10.1128/mBio.02184-18.

63. Hargreaves KR, Kropinski AM, Clokie MRJ. What does the talking? Quorum sensing signalling genes discovered in a bacteriophage genome. PLoS One. 2014;9:e85131.

64. Silpe JE, Bassler BL. Phage-encoded LuxR-type receptors responsive to host-produced bacterial quorum-sensing autoinducers. MBio. 2019;10:e00638-19.

65. Silpe JE, Bassler BL. A host-produced quorum-sensing autoinducer controls a phage lysis-lysogeny decision. Cell. 2019;176:268-80.

66. Erez Z, Steinberger-Levy I, Shamir M, Doron S, Stokar-Avihail A, Peleg Y, et al. Communication between viruses guides lysislysogeny decisions. Nature. 2017;541:488-93.

67. Rutherford ST, Bassler BL. Bacterial quorum sensing: its role in virulence and possibilities for its control. Cold Spring Harb Perspect Med. 2012;2:a012427.

68. Ji G, Beavis RC, Novick RP. Cell density control of staphylococcal virulence mediated by an octapeptide pheromone. Proc Natl Acad Sci USA. 1995;92:12055-9.

69. Davies DG, Parsek MR, Pearson JP, Iglewski BH, Costerton JW, Greenberg EP. The involvement of cell-to-cell signals in the development of a bacterial biofilm. Science (80-). 1998;280:295-8. 